\title{
VIABILIDADE DA ATUALIZAÇÃO CARTOGRÁFICA
}

Flávio Sammarco Rosa

\section{INTRODUÇÃO}

Sabe-se que os mapeamentos sistemáticos em escalas menores que 1:25.000 são de competência dos orgãos oficiais como o IBGE e a DSG e, eventualmente, executados por entidades de âmbito regional. Quando se tem necessidade de cartas em escalas maiores, para subsidiarem estudos e projetos mais detalhados de caráter local, destacam-se duas escalas de mapeamento para atender aos múltiplos fins: uma menor, do tipo 1:10.000, utilizada indiscriminadamente para áreas urbanas e rurais e outra, do tipo 1:2.000 ou 1:1.000, correspondente às áreas urbanizadas.

Embora ainda se discutam as vantagens da adoção da escala 1:2.000 ou da 1:1.000, constata-se que as informaçōes contidas nas cartas 1:1.000 são praticamente as mesmas da carta 1:2.000. Na maior parte das vezes em que se prefere a escala maior, não é pela riqueza de informaçōes ou pela melhor precisāo cartográfica; é simplesmente pela melhor disponibilidade de espaço gráfico, ficando os detalhes mais bem distribuídos na carta. Esta escala, ao ser utilizada como base cartográfica dos cadastros, permite a representação das informações com maior detalhe.

A carta 1:2.000 possui precisão cartográfica para atender às necessidades da maioria das obras de engenharia até a fase de pré-projeto. Para a fase de projeto executa-se, normalmente o levantamento em áreas específicas, bastante restritas, através da topografia clássica e de pontos de apoio no terreno, calculados segundo um plano topográfico local. (Bottura, 1975).

Submetida a questão a uma análise de custo-benefício, a opção é pela escala 1:2.000, que, na maior parte dos casos, atende às necessidades em termos de precisão cartográfica e custa significativamente mais barato. (Lima, 1978).

A atualização de uma carta em escala cadastral, automaticamente propicia a atualização da carta em es- cala menor. No entanto, é muito mais fácil de se atualizar uma carta 1:10.000 do que a planta cadastral, que, pelo fato desta conter informações sobre cada lote/edificações, precisa contar com informações muito mais detalhadas, decorrentes de um sitema bem operado, devido aos níveis de precisão e detalhamento exigidos.

O ideal é que se fizesse, anualmente, um novo recobrimento aerofotogramétrico e se procedesse à atualização através de restituição das áreas que sofreram alterações.

O custo do aerolevantamento, no entanto, inviabiliza tal procedimento e a prática tem demonstrado que um novo recobrimento só ocorre após intervalos de tempo demasiadamente longos, durante os quais não é possível ficar sem informaçōes, trabalhando com as cartas desatualizadas. A solução é suprir esta lacuna com outras informações disponíveis, até mesmo, às vezes, com sacrifício da precisão cartográfica. Afinal, na maior parte das aplicações, vale mais ter informações imprecisas do que não tê-las.

\section{DISPONIBILIDADE DA INFORMAÇÃO}

A implantação de uma sistemática de atualização contínua depende de um permanente fluxo de informaçōes que se viabiliza com uma dinâmica de trabalho do órgão responsável pela manutenção do mapeamento, expressa por um conjunto de rotinas ou procedimentos que garantem a disponibilidade das informações e a execução da atualização propriamente dita.

As informações que interessam à atualização de um mapeamento 1:2.000 são decorrentes da intervenção humana através do processo de apropriação do espaço e de evolução da construção urbana:

(") Depto. Geografia - FFLCH - USP. 
- expansão urbana através da implantação de novos loteamentos;

- desmembramentos de lotes já existentes;

- novas edificaçōes residenciais, comerciais, industriais e outras;

- reformas nas edificações existentes;

- alterações no sistema viário;

- retificação/canalização de rios e córregos;

- alteraçôes na cobertura vegetal;

- modificações na toponímia dos logradouros públicos, indústrias, edifícios públicos e outros estabelecimentos identificados na carta;

- alterações na localização de postes, árvores, bancas de jornal, caixas de correio, cabines telefônicas e outros detalhes normalmente representados na carta;

- movimentos de terra que causam alteração da altimetria.

A sistemática de atualização contínua pode ser implementada em um município isoladamente por iniciativa da própria prefeitura, onde um de seus departamentos é responsável pela operação do sistema (Setor de Cartografia), ou fazer parte de um esquema regional a exemplo da Região Metropolitana de São Paulo, na qual a entidade metropolitana se responsabiliza por gerir o Sistema Cartográfico.

As informações devem ser coletadas pelo órgão ou setor responsável pela manutenção da base cartográfica nas fontes mais originais possíveis ou seja, em primeira mão, nos orgãos ou setores que controlam cada tipo de intervenção.

A prefeitura municipal constitui a principal fonte de dados ao exercer as atividades de aprovação, fiscalização e controle dos novos loteamentos, edificaçōes e denominação de logradouros. Somente escapam ao seu controle os serviços realizados por concessionárias de serviços públicos com os quais o relacionamento é obrigatório não só para obter os dados em foco, como para melhor gestão de seu território.

Se as informações básicas necessárias à atualização das cartas já existem nos vários setores da prefeitura (parcelamento do solo, habitação, engenharia, obras, cadastro, etc), o trabalho será orientado no sentido de:

- ter acesso a essas informações;
- avaliar a sua consistência;

- efetuar vistoria em campo, se necessário;

- executar a atualização.

A experiência mostra que o acesso às informações é o primeiro desafio a enfrentar e, talvez, seja o principal problema de todo o processo de atualização. Ter as informaçōes disponíveis implica em manter uma articulação eficiente e permanente com os vários setores da prefeitura, capaz de garantir um fluxo contínuo de dados entre o setor de cartografia e os demais.

Este fluxo, certamente, não é unidirecional. Todos os setores que geram e registram essas informaçōes são também usuários de cartografia e necessitam de cartas atualizadas para o seu trabalho. Deve existir, portanto, um intercâmbio permanente entre o setor de cartografia, responsável pelo fornecimento dos mapas básicos atualizados e os demais setores, que além de usuários, fornecem as informações de sua responsabilidade.

Cartografia e cadastro devem estar intimamente ligados, pois existe uma estreita relação de interdependência entre esses dois segmentos de informação dentro de uma prefeitura: dificilmente a cartografia poderá ser continuamente atualizada sem as informaçōes provenientes do cadastro imobiliário e fiscal e dificilmente se terá um bom cadastro sem uma base cartográfica precisa e atualizada. Esta relação de interdependência implica em que a cartografia, além de fornecer a base cartográfica em escala 1:10.000 para a elaboração da Planta de Referência Cadastral, Planta Indicativa de Equipamentos Urbanos e Planta Genérica de Valores na escala 1:5.000 (EMPLASA, 1981; Fundação Prefeito Faria Lima CEPAM, 1987), tem como missão básica fornecer a base cartográfica 1:2.000 para a elaboração das Plantas-Quadra na escala 1:1.000 ou mesmo 1:500, quando necessário.

A operação e manutenção do Cadastro deve se encarregar de continuamente ir acompanhando as alteraçōes que vão ocorrendo em cada quadra fiscal através dos processos de desmembramento de lotes, da construção de novas edificações ou de reformas nas existentes. Tais registros são fundamentais para o lançamento do Imposto Predial e Territorial Urbano - IPTU a cada ano. Este é, portanto, o período no qual o Setor de Ca- 
dastro deve se programar para efetuar uma vistoria geral da cidade, revisando todas as Plantas-Quadra para efetuar as alterações que escaparam ao processo rotineiro de aprovação de lotes e edificaçōes - "os clandestinos".

Se tal procedimento não for adotado jamais a Prefeitura poderá pretender controlar eficientemente o uso e a ocupação do solo na cidade! Se convenientemente realizado, as informações acumuladas nas Plantas-Quadra serão repassadas à base cartográfica com a qual mantém uma identidade de contorno e somente se diferencia quanto às novas informações. $\mathrm{O}$ apoio da computação gráfica, como se verá depois, é fundamental para garantir agilidade e eficiência neste trabalho.

Outra fonte de informação são as concessionárias de serviços públicos de água, esgoto, energia elétrica, telefone, gás, etc. Tais entidades, geralmente empresas públicas, são responsáveis pela implantação, operação e manutenção desses serviços, e para isso mantêm cadastros de redes de distribuição e de consumidores. Sabese que muitos loteamentos e edificaçōes, ainda que clandestinos ou irregulares, são atendidos pelo abastecimento de energia elétrica e água, fazendo parte, portanto, dos cadastros das concessionárias desses serviços.

A convergência de informações, portanto, é fundamental para alimentar a sistemática de atualização contínua das bases cartográficas e dos cadastros e deve ser a meta perseguida pelo orgão gestor do sistema cartográfico: a sua primeira função é articular todos os segmentos da administração pública e, eventualmente, das empresas particulares para evitar que as informações fiquem retidas nos arquivos; em segundo lugar, a preocupação é selecionar, sistematizar, atualizar e dar o retorno aos usuários.

O Fluxograma em anexo (Fig 1), ilustra bem este processo, que, com o decorrer do tempo, deve ser uma rotina na prefeitura. Caso a sistemática de atualização esteja a cargo de um orgão externo à prefeitura, este deverá fazer esse papel articulador entre os vários setores que dispõem dos dados. Em se tratando de um orgão estatual ou regional, sem dúvida este trabalho deve se desdobrar em cada município para abranger toda a região de interesse.
É importante salientar que a Prefeitura está para o Estado como a família para a sociedade: é a célula básica onde os fatos são gerados em primeira mão; é o orgão da administração pública que está em contato direto com o território e que, em hipótese alguma, pode ficar alheia ao processo de atualização das plantas em escala cadastral. Não há como atualizar de forma econômica e contínua sem que este processo esteja ligado às atividades do cotidiano.

\section{AVALIAÇÃO DA CONSISTÊNCIA DOS DADOS}

Para um trabalho de atualização, após a coleta das informações básicas, é necessário ter-se um certo cuidado com a precisão cartográfica. Sabe-se que grande parte das plantas de loteamentos submetidos à aprovação nas prefeituras não tem precisão compatível com a escala em que são apresentadas. Sabe-se, também, que muitos projetos, na fase de implantação, sofrem alterações em relação ao aprovado. Em consequência, basear-se simplesmente nos projetos aprovados de loteamento e edificações pode prejudicar em muito a qualidade das cartas.

É necessário, portanto, que, em algum momento anterior à atualização, as informações sejam checadas em campo. A prefeitura não só deve orientar o projeto por ocasião do fornecimento de diretrizes ao loteador como deve acompanhar o processo de implantação do loteamento até a sua conclusão: o fornecimento do "habite-se" deve ser levado a sério, verificando-se realmente se a construçāo está de acordo com o projeto aprovado.

Apesar do conhecido isolamento em que cohabitam os diversos setores de uma prefeitura, é necessário que se tomem medidas de interesse comum, promovendo a integração de trabalho, de informaçōes e de procedimentos. Especialmente os setores de planejamento, obras, cadastros e cartografia devem trabalhar em conjunto para obterem sucesso no controle da expansão urbana. Como resultado desse trabalho devem ser mantidos os cadastros de logradouros, de ISS - Imposto Sobre Serviços, de áreas públicas, de equipamentos urbanos, de áreas verdes, etc. 


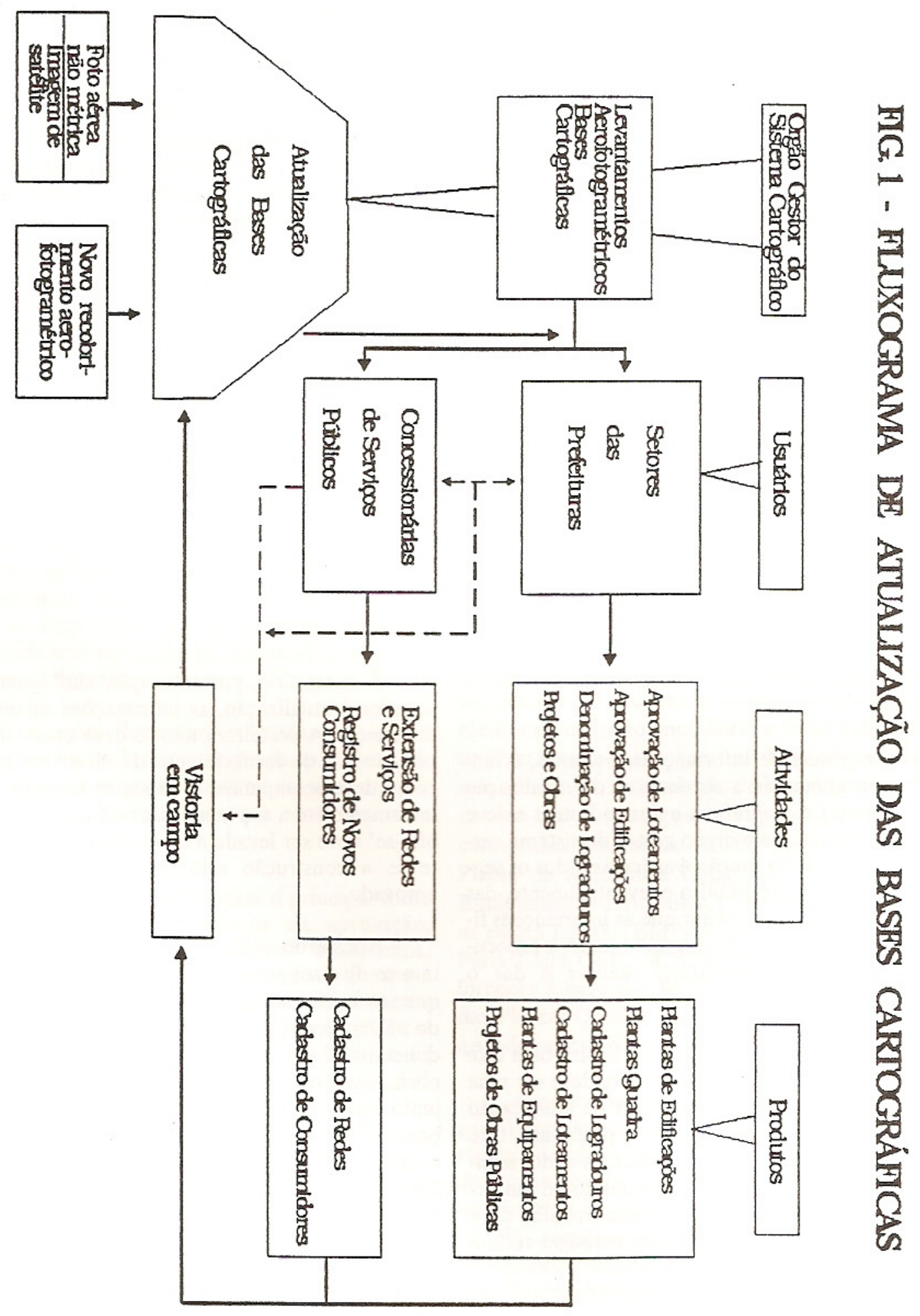


A Lei Federal, 6766/79, conhecida como Lei Lehmann, estabelece que um loteador, ao pretender efetuar um loteamento, deve solicitar à prefeitura municipal, as diretrizes que deverão orientar a execução de seu projeto, apresentando, em anexo ao requerimento, uma planta planialtimétrica da gleba, com a indicação de uma série de elementos necessários ao estudo da viabilidade do empreendimento. A prefeitura, com base no princípio estabelecido pela Lei Federal, fornecerá diretrizes sobre o uso e ocupação do solo permitidos em função de seu plano diretor (que toda cidade acima de 20.000 habitantes é obrigada a ter a partir da Constituição $\mathrm{Fe}$ deral de 1988), sobre as regras de execução e localização do sistema viário, das áreas livres, das áreas institucionais e das faixas sanitárias não edificáveis (EMPLASA \& IPT, 1987).

Caso o município faça parte da Região Metropolitana de São Paulo, conta ainda com o apoio do Decreto Estadual no 10.951 de $13 / 12 / 77$, que institui o "...Sistema Cartográfico Metropolitano como referência oficial obrigatória para todos os trabalhos de topografia, cartografia, demarcação, estudos, anteprojetos, projetos, implantação e acompanhamento das obras realizadas na Região Metropolitana da Grande São Paulo..." por orgãos ou entidades de direito público ou privado, quando o andamento ou os resultados desses trabalhos devam ser acompanhados, verificados ou aprovados por orgãos ou entidades do Sistema de Planejamento e Administração Metropolitana (EMPLASA, 1985).

Este será o momento em que a prefeitura deverá orientar o interessado quanto às especificações técnicas dos documentos cartográficos a serem elaborados com vistas à aprovação do projeto de loteamento (Rosa, F.S. 1989 - pg. 154). Além de determinar os padrōes de precisão das plantas, a prefeitura poderá solicitar que o projeto esteja referenciado ao mapeamento oficial do município e que esteja apoiado nas redes de apoio geodésico horizontal e vertical da região, o que garantirá o mínimo de precisão necessária para que as informações do projeto possam ser utilizadas com maior segurança para a atualização das cartas.

É conveniente que o setor de Cartografia disponha de uma equipe de topografia, que, entre outras tarefas que the competem, possa exercer certo controle de qualidade sobre as plantas de projetos e efetue,se necessário, o levantamento dos loteamentos e edificações clandestinos, que escapam ao tradicional controle da prefeitura.

O primeiro passo nesse sentido é saber o que está acontecendo na "clandestinidade". Seria de se esperar que o Setor de Fiscalização e Cadastro da prefeitura acompanhasse cuidadosamente o uso e a ocupação do solo de modo a ter pleno conhecimento do território sob a sua jurisdição para exercer os controles de sua competência. Isto, porém, dificilmente acontece nas cidades de maior porte e de acelerada expansão urbana, onde o número de construções clandestinas e de invasões de terras é alarmante. Na verdade, esta sistemática de atualização pode ficar comprometida se a prefeitura não tiver condições de exercer controle sobre o uso do solo de seu território. Para contornar esta situação é necessário utilizar uma metodologia que complemente as informaçōes disponíveis nos cadastros e outros setores da prefeitura. As imagens de satélite podem oferecer um grande apoio nesse sentido, ao serem utilizadas como indicativas do processo de ocupação e orientar o trabalho de campo.(ROSA, F. S. - 1989 - pg. 161).

Uma vez que as imagens orbitais ainda não apresentam resolução suficiente para a atualização das cartas em escalas grandes (1:10.000 ou maiores), dada a frequência com que podem ser obtidas, possibilitam, no entanto, um amplo monitoramento do uso do solo a nível regional, com indicações sobre algumas alterações de grande porte como arruamentos e movimentos de terra nas áreas de periferia urbana que apresentam um bom contraste em relação à vegetação que frequentemente ainda se faz presente (CARDIERI, F. L.; ROSA, F. S.; BUSCHEL, E.C.G. - 1988).

Outro recurso ainda não convenientemente explorado em áreas urbanas no Brasil, porém perfeitamente viável e de baixo custo é a utilização de fotografias aéreas não métricas obtidas com câmaras convencionais de pequeno formato instaladas em avião de pequeno porte, como mostram trabalhos realizados por LONG, D.S.; TAYLOR, J.E.\& MACCARTHY, J. - 1986; ROBERTS, A. \& GRISWOLD, L. - 1986 e ADAMS, L. P. $-1980$.

Com a utilização de alguns pontos de controle, os dados digitalizados das ampliações fotográficas em 
mesa digitalizadora podem ser satisfatoriamente corrigidos para fins de atualização das cartas.

\section{A ATUALIZAÇÃO PROPRIAMENTE DITA}

O trabalho de elaboração e gerenciamento dos mapeamentos básicos deve estar sob a responsabilidade de um setor encarregado da manutenção do sistema. Este "sistema cartográfico" deve ser entendido como o conjunto de elementos cartográficos (mapas topográficos em escalas-padrão, mapas temáticos, recobrimentos aerofotogramétricos, redes de apoio geodésico, etc.) que constituem a infra-estrutura cartográfica de apoio ao planejamento e à administração de uma região ou em outras palavras, à gestão territorial.

Algumas cartas são elaboradas através de restituição aerofotogramétrica, enquanto outras são obtidas por compilação, com informações selecionadas para determinado fim. Entre as diversas escalas que compõem um sistema, deve existir uma organicidade e uma integração tal que levem à complementaridade de funções. "O fato de cada uma destas cartas fornecer determinado tipo de informação e determinado nível de detalhamento, faz com que elas se destinem a atender objetivos específicos. O conjunto das escalas que compõem um sistema cartográfico regional deve ser estruturado de forma que haja uma inter-complementaridade de funções entre elas e uma diversificação metodológica quanto às maneiras de obtenção de cada mapeamento." (ROSA, F. S., 1989 pg. 20).

A atualização das cartas deve se processar através do aproveitamento de todas as informaçōes disponíveis desde que adequadas às diferentes escalas, onde se leva em consideração o aspecto de nível de detalhamento e de precisão cartográfica. A atualização das informaçōes planimétricas executada com informaçōes provenientes de cadastros, de projetos, de levantamentos em campo e de outras fontes disponíveis, certamente não apresenta o mesmo padrão de precisão cartográfica da restituição aerofotogramétrica original, especialmente no caso das plantas cadastrais 1:2.000. Cada nova informação plotada na carta introduz distorçōes que vão se somando no decorrer de sucessivas atualizações. Após alguns anos, cada carta deverá ser novamente restituída a partir de um novo recobrimento, para recuperar os padrões originais de precisão da planimetria e para a restituição da altimetria nos locais onde a topografia foi alterada.

O trabalho de atualização das plantas através de um processo contínuo de incorporação de novas informaçōes torna-se muito facilitado quando se utiliza o apoio computacional. A alteração dos arquivos magnéticos correspondentes a cada tema (plano de informação ou nível) que compõe a carta se torna muito mais fácil que no caso do mapa desenhado em formato convencional, com possibilidades de ajustes das convenções, cores, escala, com o trabalho de edição eletrônica e desenho automático do produto final.

Dependendo das características do município, a Prefeitura pode implantar o Sistema de Informaçōes Geográficas - SIG, mais adequado às suas condiçōes técnicas, administrativas e financeiras, obtendo grandes benefícios dos recursos tecnológicos disponíveis.

O uso da computação gráfica possibilita, ainda, introduzir as informaçōes atualizadas em um determinado nível específico de informação, o que permite manter isolados os dados da carta original, mais precisos que os dados atualizados, sem precisão cartográfica determinada.

Após vários anos, quando se realizar um novo recobrimento aerofotogramétrico, o trabalho de atualização partirá da base cartográfica original, que será atualizada através de restituição fotogramétrica, mantendo os padrões de precisão cartográfica.

Outra grande vantagem que a atualização contínua acarreta é que, facilmente, se tem a noção de quais áreas sofreram alterações e pode-se fazer um monitoramento por folha de carta, identificando quais as que se encontram demasiadamente modificadas e eivadas de erros decorrentes do processo de atualização contínua, e que necessitam de nova restituição. Isto permite determinar quando e onde é necessário efetuar o novo recobrimento aéreo e faz com que a reambulação da nova restituição se restrinja à eliminação de dúvidas do restituidor, uma vez que toda a toponímia já se encontra atualizada. 
Tal procedimento, certamente, torna o trabalho de atualização fotogramétrica bastante facilitado, com significativa redução de custos.

\section{CONCLUSĀO}

Não é possível pensar cartografia de forma isolada em um orgão da administração pública. Uma vez que ela é o registro dos vários aspectos da realidade, integrando os dados históricos e os planos futuros, ela é, também, responsável pela construção do presente.

As bases cartográficas de um município ou região devem ser disponíveis em várias escalas-padrāo para atenderem às diferentes finalidades. Ao mesmo tempo que única e confiável em cada escala, a base cartográfica deve ser compartilhada pelo maior número possível de usuários. Estes todos, por outro lado, são potencialmente produtores das informaçöes necessárias à sua atualização. Isto pressupōe a existência de um fluxo de informações no sentido do usuário e o seu retorno, no sentido do gestor da cartografia de base.

Uma prefeitura tem todas as condições de dispor de informações sobre o seu território constantemente atualizadas. Basta trabalhar de forma organizada e competente, não desperdiçando os recursos que estẩo à mão.

A integração de atividades entre os vários setores de uma prefeitura bem como a integração de informa- ções através de fluxos permanentes e consolidados em rotinas de procedimentos é fundamental para garantir a existência de cartas continuamente atualizadas, da mesma forma como isso é necessário para a manutenção de qualquer Sistema de Informações Geográficas que se pretenda implantar.

\section{RESUMO}

A necessidade de se dispor de mapeamentos básicos em escalas granđes sempre atualizados leva à implantação de uma sistemática de atualização contínua por parte dos orgãos responsáveis pela manutenção das bases cartográficas ao nível regional ou municipal.

São analisadas algumas alternativas metodológicas de atualizaçăo, propondo-se o aproveitamento de todas as informações disponíveis nos orgãos da administração pública, e mesmo em entidades particulares, através do estabelecimento de um fluxo de informaçס̃es entre produtores e usuários de cartografia para alimentaçăo do sistema.

Ressalta o papel fundamental da integração entre os vários setores das prefeituras e as concessionárias de serviços públicos para assegurar a convergência de informaçðes, sem a qual se inviabiliza o processo de atualização contínua a baixo custo.

O sucesso do trabalho de atualização depende da operação de um sistema cartográfico municipal ou regional, intimamente ligado às atividades de gestão territorial.

Palavras-chave: Atualização cartográfica; Cartografia urbana; Sistema cartográfico.

\section{BIBLIOGRAFIA}

ADAMS, L. P. The use of non-metric camaras in short-range photogrammetry. Photogrammetria, 36. Amesterdam. 1981. pp. 5160.

BARBOSA, Newton Ataliba Madsen. Compatibilização dos sistemas nacionais de cadastro, cartografia e estatística com as possibilidades e interesses do município. In: Anais. VII Congresso Brasileiro de Cartografia. São Paulo, 1975. pp. 787-800.

BOTTURA, Luís Célio. A cartografia como ferramenta de sistema de transporte. In: Anais. VII Congresso Brasileiro de Cartografia. São Paulo, 1975. pp. 497-504.

CARDIERI, Francisca Luiza G.; ROSA, Flávio Sammarco \& BUSCHEL, Elisabete Correa G. Monitoramento da expansåo urbana na Regiăo Metropolitana de Săo Paulo. In: Anais. V
Simpósio Brasileiro de Sensoriamento Remoto. Natal, 1988. Vol. 1, pp. 22-30.

EMPLASA - Empresa Metropolitana de Planejamento da Grande São Paulo S.A. Manual básico de implantação, operação e manutenção do Cadastro Técnico Municipal. São Paulo, 1981. 218 p.

EMPLASA - Empresa Metropolitana de Planejamento da Grande São Paulo S.A. Secretaria dos Negócios Metropolitanos do Estado de Săo Paulo. Legislaçăo básica de interesse metropolitano. São Paulo, 1985. 464p.

EMPLASA - Empresa Metropolitana de Planejamento da Grande Săo Paulo S.A./SNM \& IPT-Instituto de Pesquisas Tecnológicas do Estado de Săo Paulo/SICCT - Cartografia geotécnica 
aplicada ao planejamento na Grande São Paulo: loteamentos. Manual de recomendaçōes para detalhamento e apresentação de projetos. Săo Paulo, 1987.45p.

ERWES, Herbert. Sugestzes sobre as ređes geodésicas básicas para o moderno cadastro urbano e levantamentos urbanos. In: Anais. VII Congresso Brasileiro de Cartografia. São Paulo, 1975. pp. 805-820.

FUNDAÇAO PREFEITO FARIA LIMA - CEPAM. Manual de atualizaçăo de cadastro imobiliário. Superintendência de Desenvolvimento Administrativo. Săo Paulo, 1987. 96 p.

LIMA, Divaldo Galvăo; ROSA, Flávio Sammarco ; MENEZES, Luís Antonio \& ANJOS, José Vagner. Análise crítica e sugestōes sobre o documento preliminar das "Normas técnicas para cartografia regional e urbana", elaborado pela CNPU. São Paulo, 1978

LOCH, Carlos. Monitoramento Global Integrado de Propriedades Rurais - Série Didática, UFSC, Florianópolis, $1990.136 \mathrm{p}$

LONG, Daniel S.; TAYLOR, John E. \& MACCARTHY, Jack. Cessna Aircraft Cabin Door Mount for photographic and videographic camaras. Photogrammetric Enginneering and Remote Sensing, Vol. 52, ne 11, November 1986. pp. 1753-1755.

MORETTI, Ricardo de Sousa. Loteamentos: manual de recomendaçōes para elaboração de projeto. Instituto de Pesquisas Tecnológicas, Săo Paulo, 1986.180 p.
ONOFRIO, João Cesar F. Mapas para o planejamento metropolitano. In: Anais. VII Congresso Brasileiro de Cartografia. São Paulo, 1975. pp 771-785.

ROBERTS, A \& GRISWOLD, L. Practical photogrammetry from $35 \mathrm{~mm}$ aerial photography. Photogrammetric Enginneering and Remote Sensing. Vol. 52, $\mathrm{n}^{2} 4$, April 1986, pp. 501-508.

ROSA, Flávio Sammarco. Tese de Doutoramento apresentada ao Departamento de Geografia. FFLCH-USP. 1989. 208p.

ROSA, Flávio Sammarco. A fotografia aérea como instrumento de planejamento municipal e regional. In: Anais. Encontro Nacional de Sensoriamento Remoto Aplicado ao Planejamento Municipal. INPE. Campos de Jordão, 1987. pp.263-279.

ROSA, Flávio Sammarco. A restituição digital para um Sistema de Informaçōes Geográficas. Revista do Departamento de Geografia n 5, Faculdade de Filosofia Letras e Ciências Humanas USP, Săo Paulo, 1991. pp. 25-28.

VORPE, Tereza Rodrigues \& ROSA, Flávio Sammarco. Atualizaçăo do Mapeamento 1:10000 do Sistema Cartográfico Metropolitano. In: Anais. V Simpósio Brasileiro de Sensoriamento Remoto. Natal, 1988. Vol. 1, pp.105-112. 